\section{Case report of a pustular dermatitis outbreak in sheep: Clinical and food safety considerations}

\author{
Mariana Roccaro, ${ }^{1}$ Silvia Piva, ${ }^{1}$ \\ Alessandra Scagliarini, ${ }^{1}$ \\ Federica Giacometti, ${ }^{1}$ Andrea Serraino, ${ }^{1}$ \\ Giuseppe Merialdi, ${ }^{2}$ Matteo Frasnelli, ${ }^{2}$ \\ Angelo Romano, ${ }^{3}$ Alberto Bellio, ${ }^{3}$ \\ Lucia Decastelli, ${ }^{3}$ Angelo Peli ${ }^{1}$ \\ ${ }^{1}$ Department of Veterinary Medical \\ Sciences, University of Bologna; \\ ${ }^{2}$ Experimental Institute for \\ Zooprophylaxis in Lombardy and \\ Emilia Romagna, Reggio Emilia; \\ ${ }^{3}$ Experimental Institute for \\ Zooprophylaxis in Piedmont, Liguria \\ and Valle D'Aosta, Turin, Italy
}

\begin{abstract}
The objective of this report is to describe an outbreak of pustular dermatitis in a flock of about 200 sheep, its clinical evolution and food safety implications. The onset of the symptoms was sudden and the lesions spread very quickly from ewe to ewe, so that in about 3 days almost all of the lactating sheep were stricken. Pustules from 5 different animals, six milk samples, two cheese samples, teat cup samples from the milking machine and farmer's hands were analysed. A pure culture of Staphylococcus aureus, producing staphylococcal enterotoxin (SE) C, was isolated from pustules. Milk and cheese showed a contamination by coagulase positive staphylococci $<15$ and 30 colony forming units respectively and the absence of SE. Farmer's hands and teat cups samples resulted negative for coagulase positive staphylococci. Therapy with daily topical medicaments was prescribed and a prophylactic intervention was suggested by the administration of an autovaccine. The low level of milk and cheese contamination and the absence of SE in cheese supported the decision to not advise the farmer to recall cheese produced with milk from affected animals.
\end{abstract}

\section{Introduction}

Staphylococcus species are versatile pathogens of animals and humans with a worldwide distribution. Coagulase-positive strains are common large animal pathogens able to produce several toxins that cause specific illnesses. Some coagulase-positive staphylococci, particularly Staphylococcus aureus, produce termostable enterotoxins responsible for staphylococcal food poisoning (SFP), a foodborne disease characterized by symptoms like nausea, vomit and diarrhoea.

During 2015 in European Union 434 food-borne outbreaks caused by staphylococcal enterotoxins (SE) were reported, representing $9.9 \%$ of all outbreaks. In $33.3 \%$ of the 39 strong-evidence outbreaks caused by staphylococcal toxins, cheese was implicated as food vehicle (EFSA, 2016).

Sheep cheeses are often made from raw ewe's milk and, in case of contaminated milk, $S$. aureus growth and toxin production may occur during cheese production. Indeed, milk products are often contaminated by S. aureus (Normanno et al., 2005). Intramammary infections with $S$. aureus represent a main source of contamination for raw milk, but contamination could occur consequently to skin or environmental contamination or during food processing (Spanu et al., 2012).

Mastitis due to coagulase-positive staphylococci in farm animals has been deeply studied. Conversely, literature about cutaneous diseases due to staphylococci is strikingly scarce, especially for sheep. Staphylococcus spp. isolated from skin lesions are usually assumed to be commensals that have proliferated because of predisposing factors such as trauma, poor environmental conditions, poor nutrition, crowding, stress associated with parturition, parasitism or other skin diseases (Foster, 2012).

The objective of this report is to describe an outbreak of pustular dermatitis in a sheep flock, its clinical evolution and food safety implications.

\section{Materials and Methods}

\section{Clinical presentation}

On February 2017 a farmer of Massese breed and Lacaune-crossed sheep reported his lactating ewes showing skin lesions limited to the udder associated to a mild decrease of the milk yield. The onset of the symptoms was sudden and the lesions spread very quickly from ewe to ewe, so that in about 3 days almost all of the lactating sheep were stricken.

The flock of two hundred sheep was housed during winter months, bedded on straw and fed hay, barley and corn. Straw bedding was of low quality, having been stored as big bales and allowed to get wet.

Clinical examination of sick ewes was
Correspondence: Silvia Piva, University of Bologna, Department of Veterinary Medical Sciences, Via Tolara di Sopra, 50, Bologna, 40064 Ozzano Emilia, Italy.

Tel.:+39.051.2097321 - Fax: +39.051.2097346

E-mail: silvia.piva@unibo.it

Key words: Pustular dermatitis, Sheep, Staphylococcus aureus, Staphylococcal enterotoxins, Raw milk cheese.

Contributions: the authors contributed equally.

Conflict of interest: the authors declare no potential conflict of interest.

Funding: none.

Received for publication: 4 August 2017. Revision received: 6 November 2017.

Accepted for publication: 6 November 2017.

This work is licensed under a Creative Commons Attribution-NonCommercial 4.0 International License (CC BY-NC 4.0).

(C) Copyright M. Roccaro et al., 2018

Licensee PAGEPress, Italy

Italian Journal of Food Safety 2018; 7:6980

doi:10.4081/ijfs.2018.6980

carried out. The animals showed good general conditions and no pyrexia; the skin surface of the udder was reddened and covered by single to multiple white lesions, from 1 to $10 \mathrm{~mm}$ in diameter, clearly looking like pustules. Some animals exhibited crusts and flakes, the skin was thickened and milletsized nodules could be palpated. The latter manifestation was consistent with the chronic evolution of pustular lesions. Given these clinical findings, staphylococcal dermatitis was suspected (Figure 1).

\section{Diagnostic tests}

To confirm the presumptive diagnosis, microbiological analysis was carried out.

Since staphylococcal species are common skin contaminants, the sampling procedure was preceded by udder washing with soap and lukewarm water and drying with paper towels.

Pustules from 5 different animals were squeezed and the coming out material was collected with sterile dry swabs. A total of 5 samples were collected from 5 animals.

Three dry swabs were also used to test the inner surface of the milking machine teat cups in order to verify its role in the transmission of the infection and also the efficacy of the milking machine cleaning procedures.

Six milk samples from sheep $(1,2,3,4$, $5,6)$ and 2 cheese samples produced in the farm cheese factory were also collected and 
analysed. Since $S$. aureus is a causative agent of zoonosis, one swab was also collected from the farmer's hands.

All the collected swabs and milk samples were inoculated in blood-agar plates home made by Blood agar base (BD Franklin Lakes, New Jersey, USA) supplemented with $5 \%$ defibrinated sheep blood and incubated at $37^{\circ} \mathrm{C}$ for 24 hours. Isolates were identified by Matrix-assisted laser desorption ionization-time of flight mass spectrometry (MALDI-TOF MS) technology on VITEK MS system (bioMérieux, France). An antimicrobial susceptibility test was performed using the disc diffusion method for cephalotin, ampicillin, and amoxicillin/clavulanic acid using the method and the breakpoints described by CLSI (2007).

Cheese samples were tested for the enumeration of coagulase-positive staphylococci according to ISO 6888-2:1999 (International Standard Organization, 1999) and for SE presence by Ridascreen ${ }^{\circledR}$ ELISA test.

$S$. aureus strains were tested for the genes encoding SEs (sea, seb, sec, sed, see, seg, seh, sei, sej, sep and ser), using two multiplex PCR assays, according to the EURL for the CPS method (De Buyser et al., 2009a; 2009b) and for SE production by Ridascreen ${ }^{\circledR}$ ELISA test.

Teat cups and farmer's hand swabs were plated in Baird Parker medium (Biolife, Milan - Italy) and incubated at $37^{\circ} \mathrm{C}$ for 48 hours.

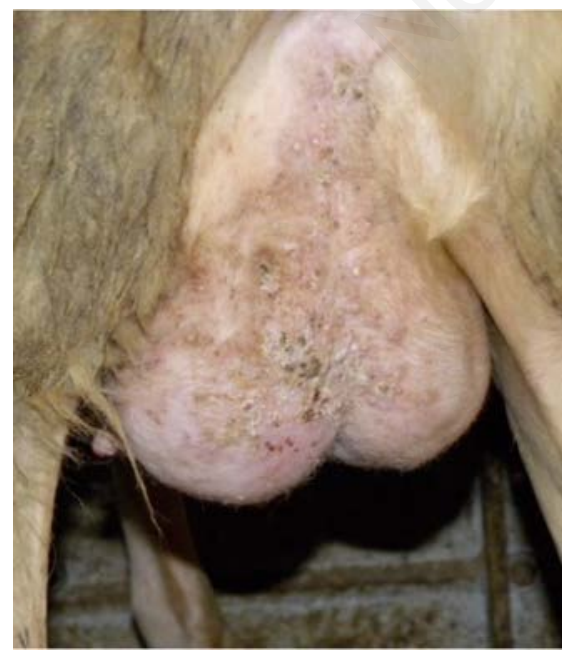

Figure 1. Clinical presentation of pustular dermatitis.

\section{Results}

From the pustules of the five sheep, a pure culture of gram positive, catalase and coagulase positive cocci was shown after 24 hours of incubation. One isolate from each sheep was identified by VITEK MS (bioMérieux, France) as $S$. aureus with a confidence value of 99.9. The isolates resulted sensitive to all the tested antibiotics.

The five $S$. aureus isolates tested for staphylococcal enterotoxin (SE) production resulted positive by Ridascreen ${ }^{\circledR}$ ELISA. All five strains resulted positive for sec gene (Figure 2). Teat cups swabs resulted negative for Staphylococcus spp. The farmer's hand swabs were positive for the presence of coagulase-negative staphylococci only. Milk samples resulted negative for $S$. aureus.

Microbiological analysis of cheese showed a coagulase-positive staphylococci count $<30 \mathrm{CFU} / \mathrm{g}$ and resulted negative for the presence of SE type A, B, C, D and E.

\section{Treatment}

The option of systemic antibacterial therapy was discarded given the requirement for milk withdrawal for lactating animals. For this reason, therapy with daily topical medicaments, that usually results in rapid healing within a few days, was prescribed. The farmer was invited to wash the udder twice a day after milking procedure and to apply an emollient antiseptic cream made of diluted povidone-iodine and glicerin. Given the zoonotic potential of $S$. aureus, the farmer was strongly recom- mended to wear gloves while handling animals and to wash his hands after contact with them.

Since it appears to be no evidence for protection from recurrence based on experimental studies (Fraser et al., 1982; Martin, 1983) a prophylactic intervention, by the administration of an auto-vaccine prepared with the same strains isolated from the animals with cultural analysis, was suggested.

\section{Discussion and Conclusions}

Enterotoxigenic Staphylococcus aureus represents a potential risk for food safety and public health. Milk products are frequently contaminated with $S$. aureus, most likely as a consequence of mastitis, but also for skin and environmental contamination.

Staphylococcal skin diseases in sheep have been well summarized by McNeil (2007), but little new information has been published after Scott's Large Animal Dermatology (1988) and almost all staphylococcal dermatitis case reports describe a severe ulcerative dermatitis involving the udder (Doherty and Bassett, 1989; Gunning and Bosworth, 1989; Gunning and Davies, 1989; Martin, 1983; Scott and Murphy, 1997; Scott et al., 1980). In our case the most recurring clinical sign was the presence on the udder of reddening, pustules and crusts with a mild decrease of milk yield.

$S$. aureus represents one of the most important causative agents of foodborne illness consequent to cheese consumption, especially for those made from raw milk in

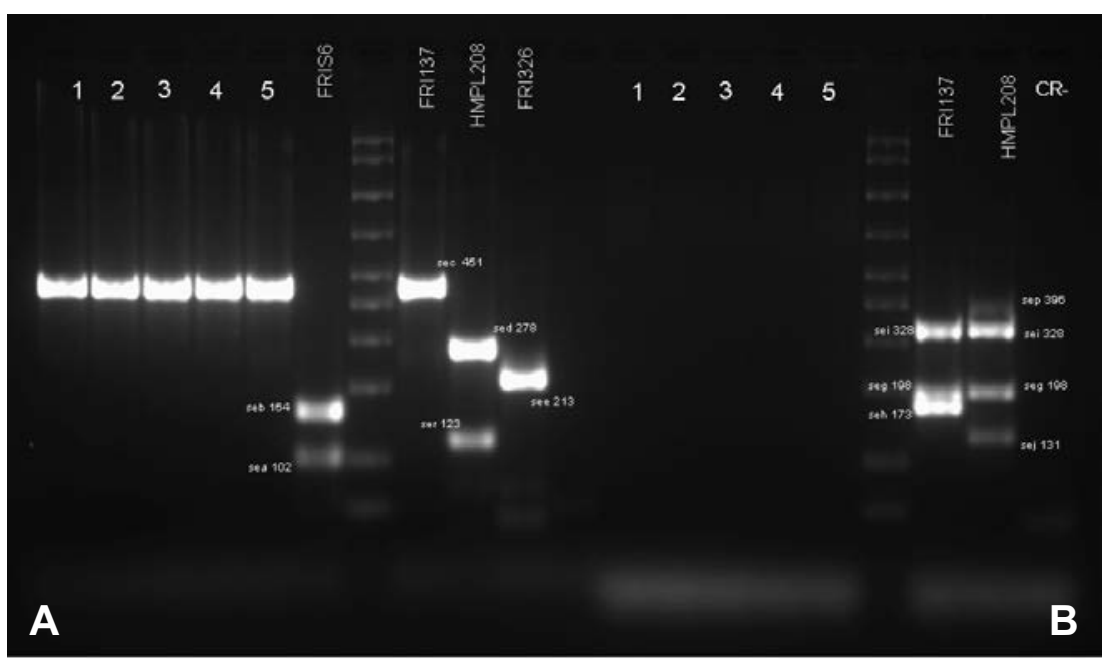

Figure 2. Results of multiplex PCR for SEs genes detection performed according to De Buyser et al. 2009a (A) and De Buyser et al. 2009b (B). 
artisanal cheese factories. Contamination of food products with $S$. aureus may result primarily from their presence in the raw material (De Buyser et al., 2001). Although during cheesemaking process several factors such as acidification and aging contribute to reduce the risk of microbial growth. It is of major interest to understand staphylococcal infection in ewes and to implement measures for minimizing the spread of this microorganism in order to control or eradicate $S$. aureus infection.

In sheep several manifestations of staphylococcal skin disease have been described and associated with S. aureus, such as periorbital eczema, folliculitis, furunculosis, scalded skin syndrome and impetigo.

Impetigo is inflammation of the interfollicular skin with development of intraepidermal pustules and crusts. Lesions occur most commonly on the udder, with the base of the teats and the intramammary sulcus most often affected. Pruritus and pain are rare, and affected animals usually suffer no systemic disturbance unless mastitis ensues (Scott, 1988). Impetigo can be spread in the flock through poor hygiene at milking and is occasionally recorded as a zoonosis with human cutaneous infections (Foster, 2012). Lesions may take weeks to heal and disease outbreaks can continue for months as infection spreads through the flock. Some flocks can be affected in consecutive years. Differential diagnoses for staphylococcal dermatitis may include contagious pustular dermatitis (parapox virus; orf), dermatophytosis, dermatophilosis and photosensitization (Foster, 2012). Since clinical signs of cutaneous staphylococcal infection are not pathognomonic and may include papules, pustules, crusts, hyperpigmentation, erythema, alopecia, confirmation of infection can be achieved only by a combination of diagnostic procedures which are rarely carried out on farm livestock because of cost. More often, veterinarians treat empirically on the basis of a presumptive diagnosis based on the history and clinical signs. Little or no treatment is required for mammary impetigo. Cleansing of the udder and cleaning of the environment may aid control by reducing the bacterial load and minimizing direct and indirect transmission of staphylococci. Systemic antibacterial therapy with injectable products is rarely needed. Furthermore, the requirement for milk withdrawal for lactating animals, when the milk is intended for human consumption, makes this therapeutic choice inconvenient for the farmer.

In any case, udder integrity and health is essential for food safety. According to the health requirements for raw milk produc- tion mentioned in the Regulation (EC) No $853 / 2004$ of the European Parliament and of the Council laying down specific rules on the hygiene of foodstuffs, raw milk must come from animals that are in a good general state of health, present no sign of disease that might result in the contamination of milk and that do not have any udder wound likely to affect the milk.

The presence of $S$. aureus in raw milk is primarily due to intramammary infections, but also to skin and environmental contamination or poor hygiene conditions during the milking procedure. However, pathogenic strains are carried by a part of healthy animals. A study in French farms showed nasal carriage of $S$. aureus in $29 \%$ of dairy ewes (Vautor et al., 2005). These organisms are a potential source of infection for skin, other organs and milk and meat contamination. The development of skin disease may depend on disturbance of the normal balance between host defences and bacterial virulence factors, for example by alteration of the local microenvironment.

During raw milk cheese production process, if favourable conditions occur, $S$. aureus may grow and produce enterotoxins, but only values $>10^{5} \mathrm{CFU} / \mathrm{g}$ are considered a risk factor for food safety. In fact, the Commission Regulation (EC) No 1441/2007 amending Regulation (EC) No 2073/2005 on microbiological criteria for foodstuffs includes coagulase-positive staphylococci among the process hygiene criteria for cheeses made from raw milk and commands testing for staphylococcal enterotoxins only whether values $>10^{5}$ $\mathrm{CFU} / \mathrm{g}$ are detected.

In the observed cases the decision to not advise the farmer to recall cheese produced with milk from affected animals was supported by several elements. Furthermore, despite the presence of udder wounds likely to affect milk, the coagulase positive staphylococci count in milk was very low $(<15 \mathrm{UFC} / \mathrm{mL})$ and the negative results of the teat cups swabs culture proved the milking and cleaning procedures carried out to be able to prevent milk contamination, as confirmed by the coagulase positive staphylococci count in cheese $(<30 \mathrm{UFC} / \mathrm{g})$ and the absence of SE in cheese.

\section{References}

Altschul SF, Gish W, Miller W, Myers EW, Lipman DJ, 1990. Basic local alignment search tool. J Mol Biol 215:403-10.

De Buyser ML, Barbara B, Maire M, Lafarge V, 2001. Implication of milk and milk products in food-borne diseases in France and in different industri- alised countries. Int J Food Microbiol 67:1-17.

De Buyser ML, Grout J, Brisabois A, Assere A, Lombard B, 2009a. Detection of genes encoding staphylococcal enterotoxins multiplex PCR for sea to see and ser. Method of the CRL for coagulase positive staphylococci, including Staphylococcus aureus. Version 1.

De Buyser ML, Grout J, Brisabois A, Assere A, Lombard B, 2009b. Detection of genes encoding Ssaphylococcal enterotoxins multiplex PCR for seg to sej and sep. Method of the CRL for coagulase positive staphylococci, including Staphylococcus aureus. Version 2.

Dohert ML, Bassett HF, 1989. Staphylococcal dermatitis in sheep. Vet Rec 124:470.

European Commission, 2004. Regulation of the European Parliament and of the Council of 29 April 2004 laying down specific hygiene rules for on the hygiene of foodstuffs, 853/2004/CE. In: Official Journal, L 139/55, 30/04/2004.

European Commission, 2007. Commission Regulation of 5 December 2007 amending Regulation (EC) No 2073/2005 on microbiological criteria for foodstuffs, 1441/2007/CE. In: Official Journal, L 322/12, 07/12/2007.

European Food Safety Authority, European Centre for Disease Prevention and Control, 2016. The European Union summary report on trends and sources of zoonoses, zoonotic agents and foodborne outbreaks in 2015. EFSA J 14:198.

Foster AP, 2012. Staphylococcal skin disease in livestock. Vet Dermatol 23:34251.

Fraser J, Scott FM, Angus KW, Martin WB, 1982. Experimental re-infection of the skin of sheep with Staphylococcus aureus. Vet Rec 11:485-6.

Gunning RF, Bosworth PA, 1989. Staphylococcal dermatitis Involving the teats of lactating ewes. Vet Rec 124:146-7.

Gunning RF, Davies CH, 1989. Isolation of Pasteurella haemolytica from teat lesions in ewes. Vet Rec 125:490.

ISO, 1999. Microbiology of food and animal feeding stuffs. Horizontal method for the enumeration of coagulase-positive staphylococci (Staphylococcus aureus and other species). Part 2: Technique using rabbit plasma fibrinogen agar medium. ISO Norm 68882:1999. International Standardization Organization ed., Geneva, Switzerland. Martin WB, 1983. Staphylococcal dermati- 
tis in sheep. Vet Ann 23:104-8.

McNeil PE, 2007. Staphylococcal skin infections. Diseases of sheep, 4th ed. Blackwell Publishing, Oxford, UK.

Normanno G, Firinu A, Virgilio S, Mula G, Dambrosio A, Poggiu A, Decastelli L, et al., 2005. Coagulase-positive staphylococci and Staphylococcus aureus in food products marketed in Italy. Int $\mathrm{J}$ Food Microbiol 98:73-9.
Scott DW, 1988. Bacterial diseases. Large Animal Dermatology. Elsevier Health Sciences, London, UK.

Scott FM, Fraser J, Martin WB, 1980. Staphylococcal dermatitis of sheep. Vet Rec 107:572-4.

Scott PR, Murphy S, 1997. Outbreak of staphylococcal dermatitis in housed lactating Suffolk ewe. Vet Rec 140:631-2. Spanu V, Spanu C, Cossu F, Virdis S,
Scarano C, De Santis EPL. 2012. Prevalence of Staphylococcus aureus strains in raw sheep milk cheese and enterotoxigenic profile. Ital J Food Saf 1:91-5.

Vautor E, Abadie G, Guibert JM, Chevalier N, Pépin M, 2005. Nasal carriage of Staphylococcus aureus in dairy sheep. Vet Microbiol 106:235-9. 